\title{
Skill execution and sleep deprivation: effects of acute caffeine or creatine supplementation - a randomized placebo-controlled trial
}

\author{
Christian J Cook ${ }^{1,34^{*}+}$, Blair T Crewther ${ }^{3 \dagger}$, Liam P Kilduff ${ }^{2 \dagger}$, Scott Drawer ${ }^{1 \dagger}$, Chris M Gaviglio $^{5+}$
}

\begin{abstract}
Background: We investigated the effects of sleep deprivation with or without acute supplementation of caffeine or creatine on the execution of a repeated rugby passing skill.

Method: Ten elite rugby players completed 10 trials on a simple rugby passing skill test (20 repeats per trial), following a period of familiarisation. The players had between 7-9 $\mathrm{h}$ sleep on 5 of these trials and between 3-5 $\mathrm{h}$ sleep (deprivation) on the other 5 . At a time of $1.5 \mathrm{~h}$ before each trial, they undertook administration of either: placebo tablets, 50 or $100 \mathrm{mg} / \mathrm{kg}$ creatine, 1 or $5 \mathrm{mg} / \mathrm{kg}$ caffeine. Saliva was collected before each trial and assayed for salivary free cortisol and testosterone.

Results: Sleep deprivation with placebo application resulted in a significant fall in skill performance accuracy on both the dominant and non-dominant passing sides $(p<0.001)$. No fall in skill performance was seen with caffeine doses of 1 or $5 \mathrm{mg} / \mathrm{kg}$, and the two doses were not significantly different in effect. Similarly, no deficit was seen with creatine administration at 50 or $100 \mathrm{mg} / \mathrm{kg}$ and the performance effects were not significantly different. Salivary testosterone was not affected by sleep deprivation, but trended higher with the $100 \mathrm{mg} / \mathrm{kg}$ creatine dose, compared to the placebo treatment ( $p=0.067$ ). Salivary cortisol was elevated ( $p=0.001$ ) with the $5 \mathrm{mg} / \mathrm{kg}$ dose of caffeine (vs. placebo).

Conclusion: Acute sleep deprivation affects performance of a simple repeat skill in elite athletes and this was ameliorated by a single dose of either caffeine or creatine. Acute creatine use may help to alleviate decrements in skill performance in situations of sleep deprivation, such as transmeridian travel, and caffeine at low doses appears as efficacious as higher doses, at alleviating sleep deprivation deficits in athletes with a history of low caffeine use. Both options are without the side effects of higher dose caffeine use.
\end{abstract}

\section{Background}

Both creatine and caffeine have found common use in sport [1-4] for a variety of training and competitive aims. Popular use of caffeine is often at high concentrations (4-9 $\mathrm{mg} / \mathrm{kg}$ ) on the basis that these are more efficacious, but the proof of this is low with individual variability and consumption habits being the more dominant factors $[5,6]$. In contrast, popular creatine supplementation dosages appear to have fallen as literature supports the contention that lower doses can be as effective as higher loading schemes, again individual variability and responsiveness being major determinants [4].

\footnotetext{
* Correspondence: Christian.cook@uksport.gov.uk

+ Contributed equally

'UK Sport Council, 40 Bernard St London, UK

Full list of author information is available at the end of the article
}

While the ability of acute caffeine to address cognitive related sleep deficits is reasonably established [7], it is only recently that creatine has demonstrated similar properties $[8,9]$. It has been suggested that sleep deprivation is associated with an acute reduction in high energy phosphates that in turn produces some degree of cognitive processing deficit [8-14]. Creatine supplementation has been shown to improve certain aspects of cognitive performance with sleep deprivation and to have some positive benefits in deficits associated with certain pathophysiologies [13,14]. If sleep deprivation is associated with an energy deficit then errors in performance are perhaps more likely to occur when concentration demands are high and/or for prolonged periods of repeated task execution. Some evidence suggests that it is tasks of this nature that are most affected by acute sleep deprivation [15]. 
Creatine has generally only been used in chronic loading protocols. However, if the contention that acute sleep deprivation reduces brain creatine is true, than an acute dose of creatine, as opposed to the classical longer loading periods, may alleviate some of these effects. This would be dependent on creatine uptake not being rate limited, something unknown for the brain. Creatine does however readily cross the blood brain barrier and chronic systemic loading does appear to increase brain stores $[13,14]$. Acute doses of caffeine appear most beneficial at around 30-90 min prior performance [16] and while the timing of an acute dose of creatine has yet to be determined, it appears to take at least an hour for absorption into the bloodstream [17-19].

Sleep deprivation is not uncommon around competition in sport particularly with the frequent demands of international travel. Assessing its effects on performance is however difficult, especially in team sports where multiple physical and skill components are involved. While overt physical components such as power don't appear affected by acute deprivation [20] a few studies do however suggest acute deprivation can affect certain sport skill and physical performance $[21,22]$.

Given the potential usefulness of safe supplementation for alleviating cognitive deficits associated with sleep deprivation, this study aimed to investigate if acute administration of creatine or caffeine could offer this advantage. To this end, we tested the effects of acute occurring sleep deprivation on a fundamental rugby skill, passing the ball while running with accuracy, in elite level players. Further to this, we tested if acute administration of creatine or caffeine would in any way alter this performance.

\section{Method}

\section{Subjects}

Ten professional rugby backs (mean $\pm \mathrm{SD}$, age; $20 \pm 0.5$ years) that were in good health and injury-free volunteered for this trial. Subject bodyweights were $90 \pm 4 \mathrm{~kg}$ and heights $1.81 \pm 0.02 \mathrm{~m}$ (mean $\pm \mathrm{SD}$ ). Bodyweights showed no significant changes over the course of this trial. A within-treatment design was used with each subject acting as their own control to improve reliability and the sensitivity of measurements. Subjects all reported a low and infrequent history of both previous caffeine use (in any form) and each had used creatine previously, usually in a classic loading protocol. The athletes were all very low and infrequent social consumers of alcohol. A university ethics committee approved the study procedures and each subject signed an informed consent form before participation.

\section{Study design}

A blinded, repeated measure, placebo-controlled crossover design was used to examine the effects of acute supplementation (caffeine or creatine) on the execution of a repeated rugby passing skill during sleep deprivation.

\section{Testing procedures}

On days of testing the subjects consumed the same breakfast which consisted of a bowl of cereal with fruit, yoghurt and milk in a portion of voluntary choice and two poached eggs on one piece of buttered toast consumed between $0700 \mathrm{~h}$ and $0800 \mathrm{~h}$. Water was available ad libitum. On the night previous to testing food was not strictly controlled but all subjects reported consuming a dinner of at least red meat and 3 vegetables and a latter evening protein milkshake.

Initially all 10 players in this study undertook 3 weeks of familiarisation training on a rugby-specific passing skill (total of 12 sessions). Changes in performance and variability were calculated over these sessions. Familiarisation was undertaken at $1130 \mathrm{~h}$ each time, and required 2 previous nights of greater than $7 \mathrm{~h}$ sleep to be performed (i.e. clearly non-sleep deprived). Following familiarisation the players were asked to keep a sleep $\log$ to record the number of hours slept per night. This was reported at $0900 \mathrm{~h}$ on Monday to Friday.

The skill testing procedures were performed on 10 separate occasions across a 10 week period (not less than three days apart) at $1130 \mathrm{~h}$, with between 7-9 h sleep for two nights preceding five of these tests, and with $3-5 \mathrm{~h}$ sleep (sleep deprived) on the night preceding (but more than $7 \mathrm{~h}$ on the previous night) on the other 5 trials. At $1000 \mathrm{~h}$ on the test days the athletes received one of the following: placebo tablets (sucrose at $5 \mathrm{mg} / \mathrm{kg}$ ); creatine monohydrate tablets (50 or $100 \mathrm{mg} / \mathrm{kg}$ bodyweight); caffeine tablets ( 1 or $5 \mathrm{mg} / \mathrm{kg}$ bodyweight). Thus, the absolute mean dosages of creatine used were $4.5 \mathrm{~g}$ and $9 \mathrm{~g}$, respectively, and caffeine dosages of $90 \mathrm{mg}$ and $450 \mathrm{mg}$ were respectively used. The doses were divided into 5 tablets, of same size based upon each individual athlete's bodyweight at the start of the trial, across all treatments. Maize starch was used where necessary to balance out tablet weights and tablets were hand made using gelatine capsules. Treatment (blinded) was randomised across athletes and the skill execution tests.

On all trials subjects refrained from alcohol consumption for at least $48 \mathrm{~h}$ prior to testing and from any caffeine and caffeine containing drinks for at least $24 \mathrm{~h}$ (athletes were infrequent caffeine drinkers). The athletes recruited had not used creatine or creatine-based supplements within the preceding 3 months of this study.

\section{Rugby passing skill test}

The repeated rugby passing skill was performed indoors and consisted of: a $20 \mathrm{~m}$ sprint in which at the $10 \mathrm{~m}$ mark the player had to attempt to pass a rugby ball left or right (alternating) through a hanging hoop (diameter 
$1.5 \mathrm{~m}) 10 \mathrm{~m}$ away from them. Players were also asked to identify their better passing side (dominant). All 10 players clearly believed they had a better passing side, and this was supported by alternate accuracy. The $20 \mathrm{~m}$ protocol had to be completed in less than $20 \mathrm{~s}$ (beep timed for the players) and they undertook 20 repeats (10 passes on each side) with a walk back recovery period. Execution success was simply defined as the number of successful attempts on the dominant and nondominant side. The elite group of athletes were familiar with this common rugby skill and thus, a high level of reliability was expected. To further ensure high test-retest reliability, three weeks of familiarization sessions were also performed before the main testing procedures.

\section{Saliva measures}

Saliva was collected immediately before each trial as follows: players provided a passive drool of saliva into sterile containers (LabServe, NewZealand) approximately $2 \mathrm{ml}$ over a timed collection period ( $2 \mathrm{~min}$ ). The saliva samples were aliquoted into two separate sterile containers (LabServe, New Zealand) and stored at $-80^{\circ} \mathrm{C}$ until assay. Samples were analysed in duplicate using commercial kits (Salimetrics LLC, USA) and the manufacturers' guidelines. The minimum detection limit for the testosterone assay was $2 \mathrm{pg} / \mathrm{ml}$ with intra- and inter-assay coefficients of variation (CV) of $1.2-12.7 \%$. The cortisol assay had a detection limit of $0.3 \mathrm{ng} / \mathrm{ml}$ with intra- and inter-assay CV of $2.6-9.8 \%$.

\section{Statistical Analyses}

The accuracy of skill execution with sleep deprivation and treatments was examined using a two-way analysis of variance (ANOVA) with repeated measures on both the dominant and non-dominant passing sides. A two-way repeated measures ANOVA was also used to evaluate the effects of sleep state, treatments and any interactions for each hormonal variable. In addition, dominant versus non-dominant side skill performance during familiarisation trials and non-deprived performance versus familiarisation performance were examined similarly. The Tukey HSD test was used as the post hoc procedure where appropriate. Significance was set at an alpha level of $\mathrm{p} \leq 0.05$.

\section{Results}

Familiarisation training and dominant versus nondominant passing side

A significant main effect for skill performance was identified over time $[F(5,108)=38.44, \mathrm{p}<0.001]$. Skill execution on both sides improved significantly $(\mathrm{p}<0.001)$ across the first 5 sessions (Table 1) and then was unchanged between session 5 and 12. Variability within an individual on nonsleep deprived days was less than $5 \%$ and, between
Table 1 Accuracy, out of 10 attempts (20 total per trial), for each of dominant and non-dominant passing sides on the first, fifth and twelve familiarisation trials

\begin{tabular}{lccc}
\hline & $\mathbf{1}^{\text {st }}$ Trial $^{\text {th }}$ & Trial $^{\text {a }}$ & $\mathbf{1 2}^{\text {th }}$ Trial $^{\mathbf{a}}$ \\
\hline Dominant & $7.3 \pm 0.8$ & $9.0 \pm 0.7$ & $9.0 \pm 0.4$ \\
Non-dominant $^{b}$ & $5.7 \pm 0.8$ & $8.3 \pm 0.8$ & $8.2 \pm 0.7$ \\
\hline
\end{tabular}

Data presented as mean \pm SD.

a significantly different from the $1^{\text {st }}$ trial $(p<0.001)$, ${ }^{b}$ significantly different from the dominant side $(p=0.013)$.

individuals in the group, was less than $15 \%$ and no significant differences were seen. A significant main effect was also identified for passing side $[F(1,108)=53.85$, $\mathrm{p}<$ 0.001 ] with dominant side skill execution found to be superior to the non-dominant side across all trials $(\mathrm{p}=$ $0.013)$. No interactions between passing side and time were found $[F(5,108)=1.899, \mathrm{p}=0.1]$.

\section{Placebo non-sleep deprived versus familiarisation}

Placebo administration on non-sleep deprived days did not produce a significantly different performance result to that seen in the last familiarisation trial $[F(1,36)=0.00, \mathrm{p}=$ 1.0], but a significant main effect was identified for passing side skill execution, this being consistently higher on the dominant side than the non-dominant side $[F(1,36)=$ $22.737, \mathrm{p}<0.001]$. No significant interactions were identified for these variables $[F(1,36)=0.00, \mathrm{p}=1.0]$.

\section{Placebo versus creatine or caffeine on dominant passing side}

Repeated analyses revealed significant main effects for treatment condition $[F(4,90)=19.303, \mathrm{p}<0.001]$, sleep state $[F(1,90)=19.472, \mathrm{p}<0.001]$ and their interactions $[F(4,90)=7.978, \mathrm{p}<0.001]$ on the dominant passing side (Figure 1). All of the caffeine and creatine doses produce a significant enhancement in skill performance when compared to placebo administration ( $p<0.001)$. In the placebo condition, passing skill performance was found to be superior in the non-sleep deprived than the sleep deprived trial $(\mathrm{p}<0.001)$.

\section{Placebo versus creatine or caffeine on non-dominant passing side}

On the non-dominant passing side (Figure 2), significant main effects were identified for the treatment conditions $[F(4,90)=14.871, \mathrm{p}<0.001]$, sleep state $[F(1,90)=$ $18.228, \mathrm{p}<0.001]$, and their interactions $[F(4,90)=$ $6.026, \mathrm{p}<0.001]$. As with the dominant passing side, all of the caffeine and creatine doses produce a significant enhancement in skill performance from the placebo $(\mathrm{p}<$ 0.001 ) and, in the placebo condition, greater performance accuracy was noted in the non-sleep deprived (vs. sleep deprived) trial $(\mathrm{p}<0.001)$.

Figures 1 and 2 summarise this data. 


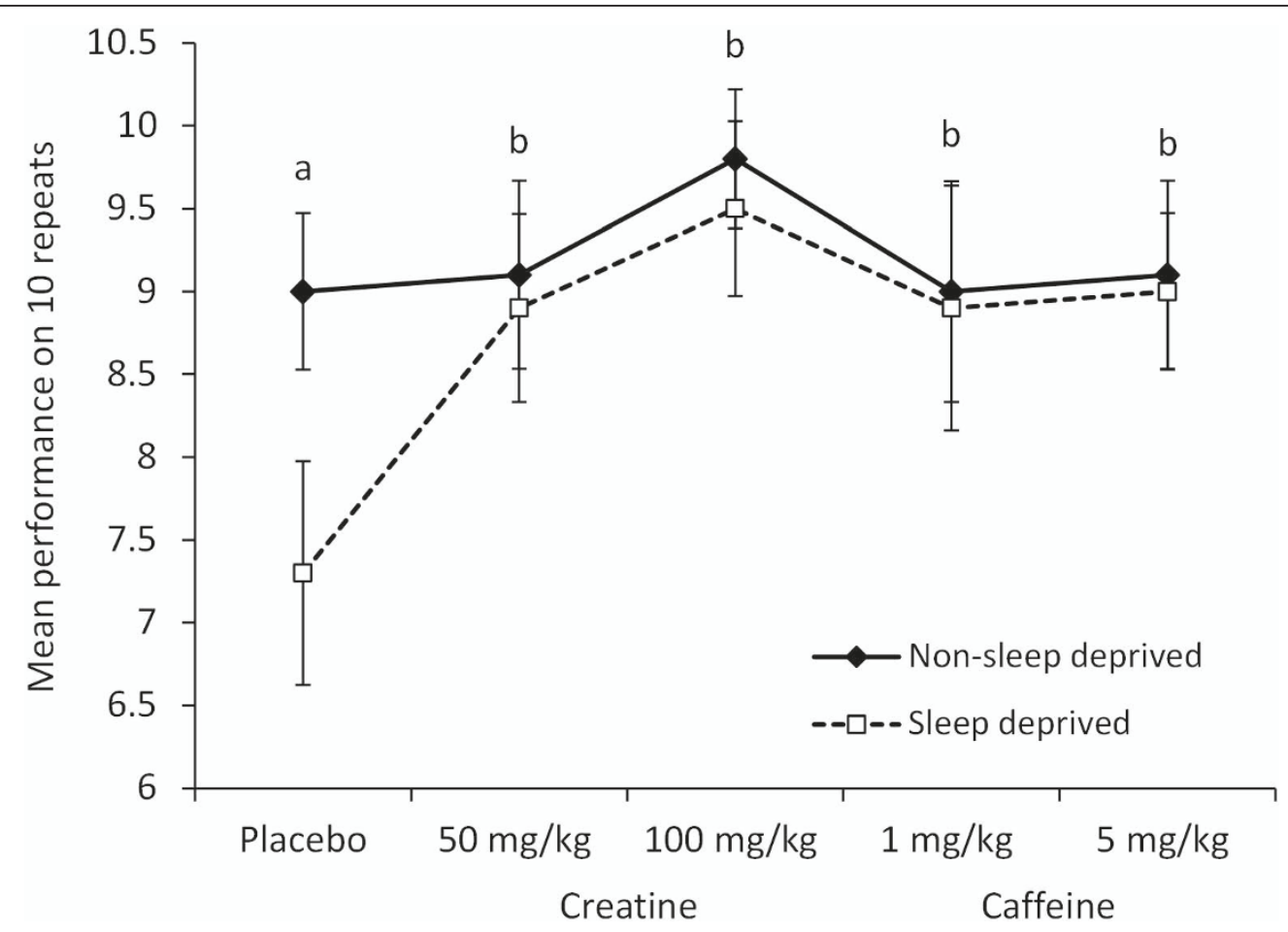

Figure 1 Effects of sleep deprivation and acute supplementations on passing accuracy (dominant side). The mean \pm SD is displayed for accuracy out of 10 passes on the dominant side (20 passes total per trial) for the 10 subjects under different treatment conditions (placebo; 1 or $5 \mathrm{mg} / \mathrm{kg}$ caffeine, 50 or $100 \mathrm{mg} / \mathrm{kg}$ creatine) either in non-sleep deprived or sleep deprived states. Dominant was chosen by the subjects as the side they believed showed better passing accuracy. All subjects completed 20 repetitions of the passing skill per trial, alternating passing sides (10 on dominant side). With placebo treatment sleep deprivation was associated with a significant fall in performance (a) ( $p<0.001)$ compared to non-sleep deprivation. The 50 and $100 \mathrm{mg} / \mathrm{kg}$ creatine and 1 and $5 \mathrm{mg} / \mathrm{kg}$ caffeine doses were all associated with a significantly better performance $(b)(p<0.001)$ than the placebo conditions.

\section{Salivary testosterone and cortisol}

A significant main treatment effect $[F(4,90)=4.855, \mathrm{p}=$ $0.001]$ was identified for salivary testosterone (Figure 3 ), trending towards higher values after the $100 \mathrm{mg}$ creatine dose $(\mathrm{p}=0.067)$ than the placebo condition. There were no significant effects of sleep state $[F(1,90)=1.602, \mathrm{p}=$ $0.209]$, nor any interactions $[F(4,90)=1.014, \mathrm{p}=$ $0.405]$, on salivary testosterone. For salivary cortisol (Figure 4), significant results were noted for the main effects of treatment $[F(4,90)=8.415, \mathrm{p}<0.001]$ and sleep state $[F(1,90)=31.31, \mathrm{p}<0.001]$, but there were no interactions $[F(4,90)=0.691, \mathrm{p}=0.6]$. Cortisol was significantly higher with the $5 \mathrm{mg}$ caffeine dose ( $\mathrm{p}=$ 0.001 ) than the placebo treatment.

Figures 3 and 4 summarise this data.

\section{Discussion}

Acute sleep deprivation is a common occurrence in the general population [23] including elite athletes. Such deprivation has been shown to affect some, but not all, physical and skill executions [15,20-22]. However, quantifying an effect in a team sport can be difficult. The repeated passing skill test we described herein is simple to perform, has sport-specific relevance and appears to be highly reliable across repeat testing. It is not however a one off, high-level performance task, rather a repeat of 20 fairly simple tasks, alternating passing sides. While we don't claim it to be in any way, yet, a valid performance measure it did reveal some interesting differences across acute sleep deprivation and across caffeine and creatine treatments.

In line with observations in other skill and psychomotor testing acute sleep deprivation reduced the accuracy over repeated trials. There was a general trend to a drop-off in accuracy latter in the repeats (second 10 of the 20 repeats). Whether this is a greater susceptibility to mental fatigue or not remains an interesting question, as does whether single skill repeats separated by more recovery time or by a similar physical activity with no real skill requirement would show a deficit in performance or not. In non-sport related psychomotor trials there is little evidence that a single episode of sleep deprivation produces significant deficit in a single task [15]; however across repeat tasks it is perceived that much greater effort is needed to maintain concentration [24]. 


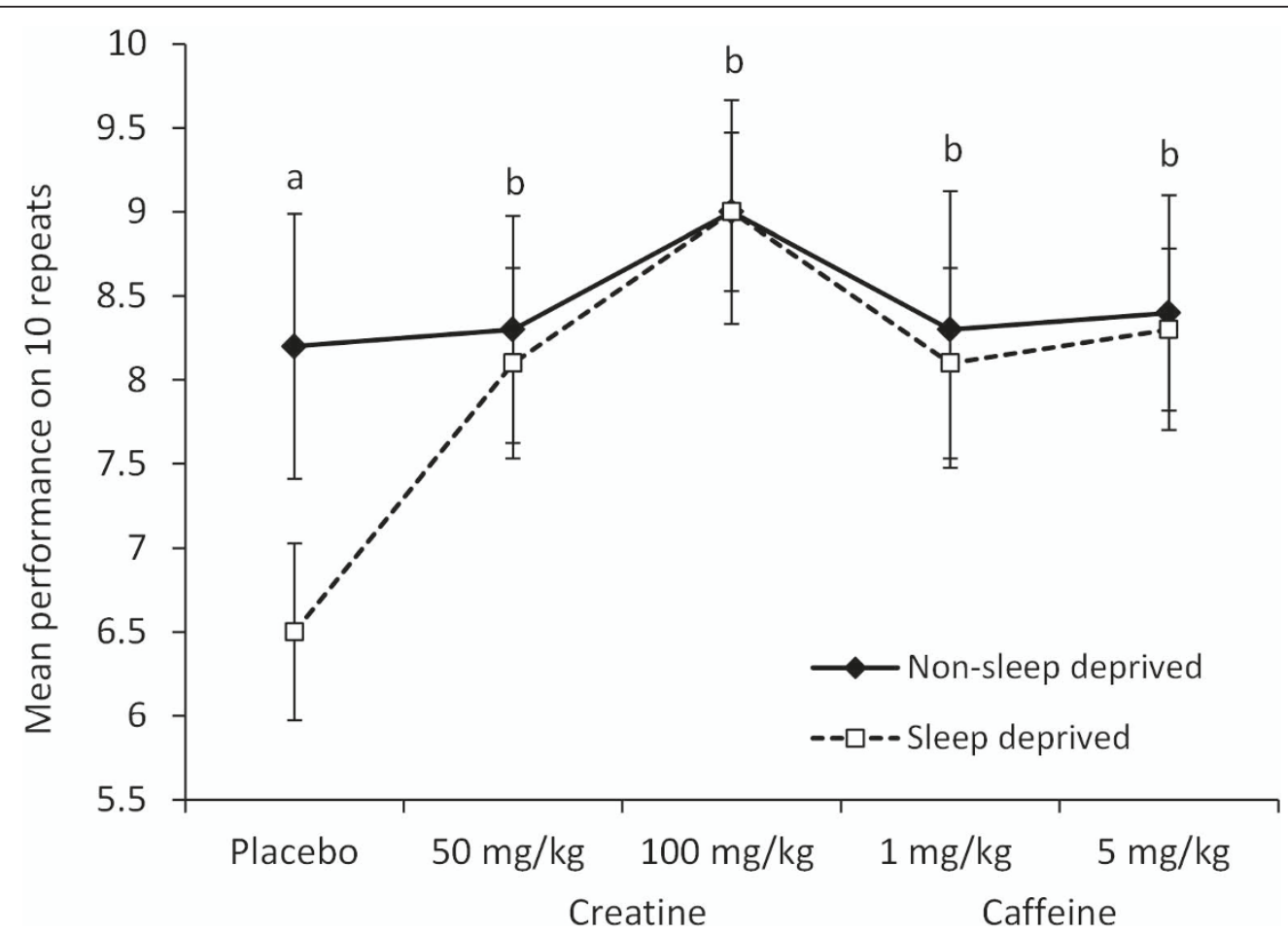

Figure 2 Effects of sleep deprivation and acute supplementations on passing accuracy (non-dominant side). The mean \pm SD is displayed for accuracy out of 10 passes on the non-dominant side (20 passes total per trial) for the 10 subjects under different treatment conditions (placebo; 1 or $5 \mathrm{mg} / \mathrm{kg}$ caffeine, 50 or $100 \mathrm{mg} / \mathrm{kg}$ creatine) either in non-sleep deprived or sleep deprived states. All subjects completed 20 repetitions of the passing skill per trial, alternating passing sides (10 non-dominant side). With placebo treatment sleep deprivation was associated with a significant fall in performance (a) $(\mathrm{p}<0.001)$ compared to non-sleep deprivation. The 50 and $100 \mathrm{mg} / \mathrm{kg}$ creatine and 1 and $5 \mathrm{mg} / \mathrm{kg}$ caffeine doses were all associated with a significantly better performance $(b)(p<0.001)$ than the placebo conditions.

Acute sleep deprivation has little effect on weightlifting performance [20], but can influence mood negatively [24] which may be a driving feature in mental performance changes. Caffeine, for example, has been shown to improve both mood and mental function following sleep deprivation [25]. It is not known how much mood and other cognitive function, particularly motivation on repeat skill tasks, interact. At the doses and administration time of caffeine use in this study we saw no evidence of an effect in non-sleep deprived subjects; however, there was a clear amelioration of skill performance deficit from the sleep-deprived trials with placebo administration. The psychostimulant effects of caffeine appear to be related to the pre and post synaptic brakes that adenosine imposes on dopaminergic neurotransmission by acting on different adenosine receptor heteromers [26], although numerous mechanisms are likely to be involved.

We did not see a dose related effect with caffeine supplementation, with $1 \mathrm{mg} / \mathrm{kg}$ and $5 \mathrm{mg} / \mathrm{kg}$ producing similar effects, nor did we see high individual variance (i.e. responders and non-responders). The absorption of caffeine in plasma following consumption has been estimated at between 30 and 90 min with half life of several hours [16], so the time between consumption and testing $(90 \mathrm{~min})$ in this study may have been too long to see all effects of differing caffeine dose, or any effect on non-sleep deprived performance. Nonetheless, at $90 \mathrm{~min}$ there was still clear evidence of a reduction in the effect of sleep deprivation on the skill measured and no evidence this was different between the 1 and $5 \mathrm{mg} / \mathrm{kg}$ dose.

Subjectively, a number of the subjects reported feeling slightly nauseous and anxious following the 5 , but not 1 , $\mathrm{mg} / \mathrm{kg}$ administration of caffeine suggesting in other ways there were dose differences. Effective doses of caffeine (and their dose response nature) remain contentious in literature $[1,5,6,27]$ possibly reflecting larger inter-subject variability in responses and different sensitivities of various physical and behavioural expressions. The subjects in this study were not regular caffeine users so arguably may have been more sensitive to lower doses than would be seen in more regular consumers. Certainly in the study herein $1 \mathrm{mg} / \mathrm{kg}$ was as effective as $5 \mathrm{mg} / \mathrm{kg}$ and from a practical perspective runs less risk of undesirable dose related side effects.

Chronic creatine supplementation has been shown to address certain aspects of sleep deprivation linked 


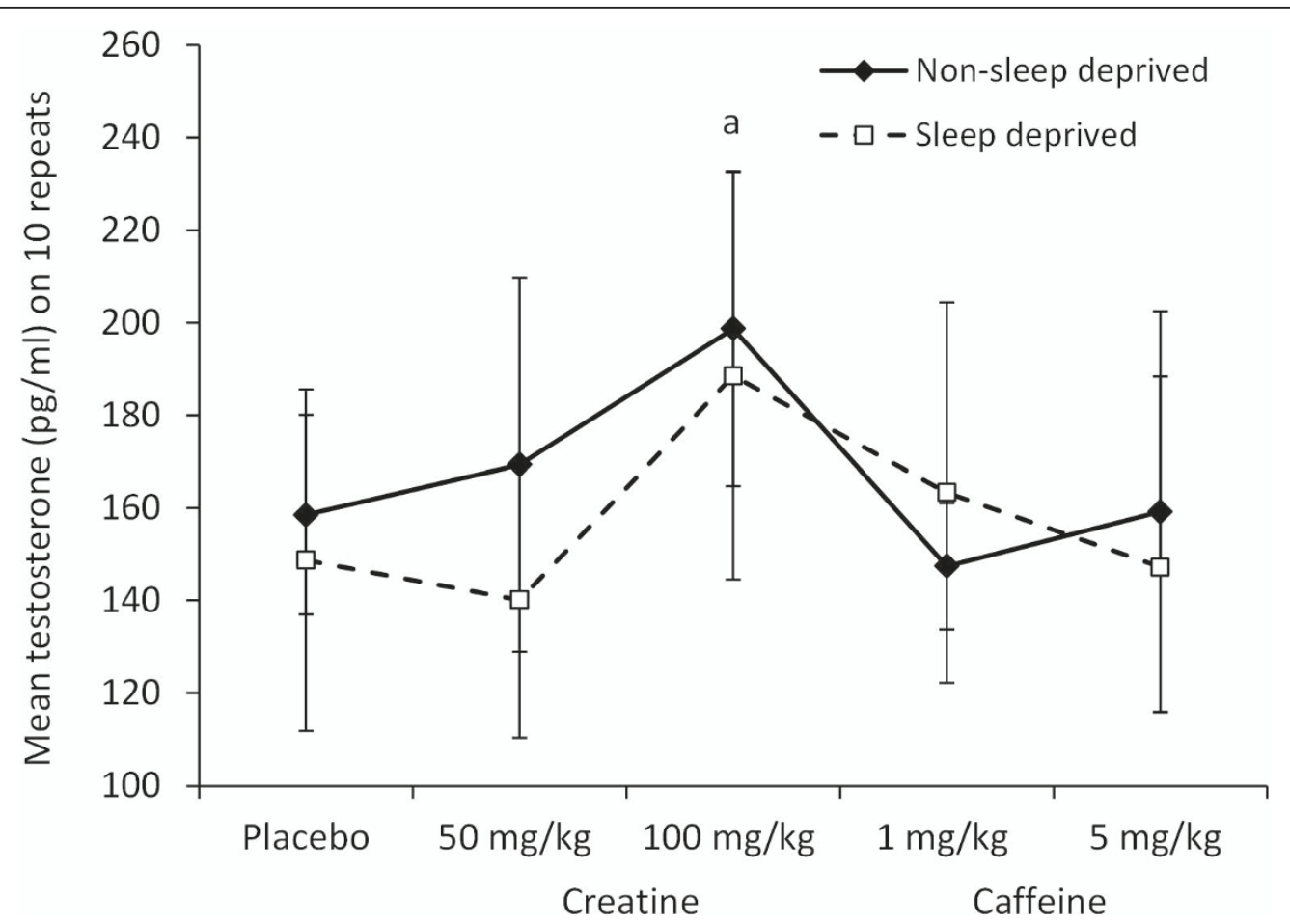

Figure 3 Pre-trial salivary free testosterone $(\mathbf{p g} / \mathbf{m l})$ across treatments. The mean \pm SD is displayed for salivary testosterone under different treatment conditions (placebo; 1 or $5 \mathrm{mg} / \mathrm{kg}$ caffeine, 50 or $100 \mathrm{mg} / \mathrm{kg}$ creatine) either in non-sleep deprived or sleep deprived states. The $100 \mathrm{mg} / \mathrm{kg}$ creatine dose was associated with a higher concentration of testosterone (a) $(p=0.067)$ compared to the placebo treatment.

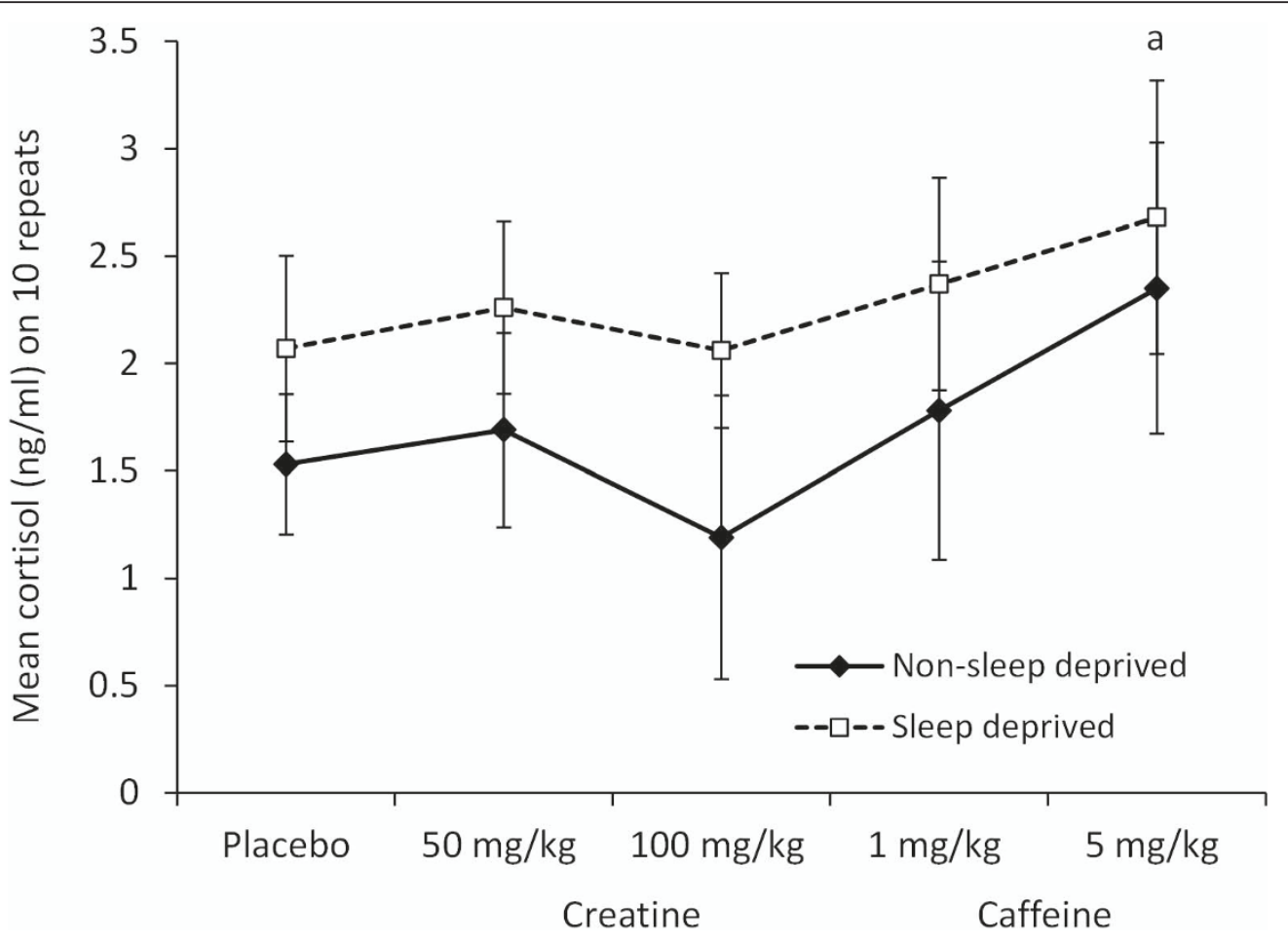

Figure 4 Pre-trial salivary free cortisol $(\mathbf{n g} / \mathbf{m l})$ across treatments. The mean \pm SD is displayed for salivary cortisol under different treatment conditions (placebo; 1 or 5 mg/kg caffeine, 50 or 100 mg/kg creatine) either in non-sleep deprived or sleep deprived states. The $5 \mathrm{mg} / \mathrm{kg}$ caffeine dose was associated with a significantly higher concentration of cortisol (a) $(p=0.001)$ compared to the placebo treatment. 
and other pathophysiology linked cognitive deficits $[8,9,11,13,14,19]$, although very low dose chronic supplementation does not appear to improve function in nonsleep deprived healthy subjects [28]. Sleep deprivation is associated with a reduction in brain stores of phosphocreatine [10] and certainly in some disease states depletion of high energy phosphate stores has been measured, associated with cognitive deficit, and alleviated to some extent by creatine supplementation $[13,14,29]$. Interestingly, if there is an energy deficit associated with sleep deprivation then it seems logical to contend that repeat trials would be more susceptible than one off tasks. Our results and indeed other work on sleep deprivation do fit this pattern. If such depletion occurs and is acute, it also stands to reason that acute supplementation (as opposed to longer protocols) would address any associated deficit (given that brain uptake is not a time limiting factor). Little, if any, attention has been given to acute dosing with creatine, mainly because it is assumed that its effects come from a gradual build up of stores over time. We demonstrate here that an acute dose of creatine can ameliorate sleep deprived deficits in repeat skill performance trials. Again this possibly reflects the repeat nature of the trials and may not be observable in an acute one off mental skill performance.

Further in contrast to caffeine administration, the creatine dose of $100 \mathrm{mg} / \mathrm{kg}$ appeared to elicit a trend towards greater effect in skill performance than $50 \mathrm{mg} / \mathrm{kg}$ dosing, thereby suggesting potentially a dose dependent response. As in the case of caffeine we observed no individual variability suggestive of responders and nonresponders or differential dose susceptibility, and no adverse effects were reported to us by the subjects. Clearly at the level of muscle function there does appear to be a division into responders and non-responders to longer term supplementation with different creatine protocols [4]. It is possible that this would be similar with longer term supplementation aimed at skill improvement, or alternatively brain-related creatine stores may operate slightly differently to muscle.

Acute sleep deprivation has been demonstrated in some studies to have small disruptive effects on basal hormonal concentrations [30,31]. Although salivary cortisol appeared to be elevated with sleep deprivation, this result did not reach statistical significance. Interestingly the higher dose of caffeine was associated with significant elevation in pre-trial cortisol, but not testosterone. High doses of caffeine have previously been demonstrated to acutely increase cortisol and, to a lesser extent, testosterone [20,32]. Whether such elevations have any significance in outcome is unknown. Cortisol is associated with arousal but also with anxiety [33]. Unfortunately we did not concurrently measure salivary alpha amylase in this study, which may also be a useful marker with respect to system arousal [34]. Testosterone was unaffected by sleep deprivation and by all treatments except the high dose of creatine, where there was a trend towards higher concentrations. We do not have useful speculation as to why this increase was seen, although it was across all subjects. Still, the increase was relatively small in magnitude and we doubt at this stage that it has any real physical or behavioural consequence. As we used saliva measures we cannot rule out some local oral cavity artefact effect of creatine. Free testosterone levels have, however, been linked to intra-individual variance in short timeframe muscular power [35], and long-term creatine supplementation has been reported as influencing testosterone metabolite pathways [36], so the observation is perhaps worthy of some follow-up.

Little has been published on acute creatine use as it has primarily been regarded as a longer term supplement to muscular function gain. In terms of brain and behavioural function it would appear it have some acute effects of value. It is also possible that the observed effects of caffeine and creatine reported in this and other studies are potentially summative and thus, would seem a logical progression for research.

\section{Conclusions}

We observed a significant effect of acute sleep deprivation on performance (on both dominant and nondominant passing sides) of a repeat simple skill test in elite rugby players. The deficit in performance with sleep deprivation was addressed by acute supplementation with either caffeine or creatine. In both cases, the two dosages tested had similar effects on skill performance. Both may offer practical and viable options prior to training and competition to assist skill performance when sleep loss has occurred.

\section{Acknowledgements \\ We acknowledge with gratitude the professional athletes that contributed to this study. In part this study was supported by grants (ESPRIT) from Engineering and Physical Sciences Research Council UK and by UK Sport Council. \\ Author details \\ ${ }^{1}$ UK Sport Council, 40 Bernard St London, UK. ${ }^{2}$ Sport and Exercise Science Research Centre, Swansea University, Swansea, UK. ${ }^{3}$ Hamlyn Centre, Institute of Global Health Innovation, Imperial College, London, UK. ${ }^{4}$ Department for Health, University of Bath, Bath, UK. ${ }^{5}$ Queensland Academy of Sport and Gold Coast SUNS, AFL Franchise Gold Coast, Brisbane, Australia.}

\section{Authors' contributions}

CJC participated in protocol design, conduct of the study, data analyses and manuscript preparation. LPK, CMG, SD and BC participated in protocol

design, data analyses and manuscript preparation. All authors have read and approved the final manuscript.

\section{Competing interests}

The authors declare that they have no competing interests.

Received: 31 August 2010 Accepted: 16 February 2011

Published: 16 February 2011 
References

1. Burke LM: Caffeine and sports performance. Appl Physiol Nutr Metab 2008, 33:1319-34.

2. Woolf K, Bidwell WK, Carlson AG: Effect of caffeine as an ergogenic aid during anaerobic exercise performance in caffeine naive collegiate football players. J Strength Cond Res 2009, 23:1363-9.

3. Astorino TA, Roberson DW: Efficacy of acute caffeine ingestion for shortterm high-intensity exercise performance: a systematic review. J Strength Cond Res 2010, 24:257-65.

4. Kilduff LP, Pitsiladis YP, Tasker L, Attwood J, Hyslop P, Dailly A, Dickson I, Grant S: Effects of creatine on body composition and strength gains after 4 weeks of resistance training in previously non resistance-trained humans. Int J Sport Nutr Exerc Metab 2003, 13:504-20.

5. Skinner $T L$, Jenkins DG, Coombes JS, Taaffe DR, Leveritt MD: Dose response of caffeine on 2000-m rowing performance. Eur J Appl Physiol 2009, 107:155-61.

6. Jenkins NT, Trilk UL, Singhal A, O'Connor PJ, Cureton KJ: Ergogenic effects of low doses of caffeine on cycling performance. Med Sci Sports Exerc 2010, 42:571-6.

7. McLellan TM, Bell DG, Kamimori GH: Caffeine improves physical performance during $24 \mathrm{~h}$ of active wakefulness. Aviat Space Environ Med 2004, 75:666-72

8. McMorris T, Harris RC, Howard AN, Langridge G, Hall B, Corbett J, Dicks M, Hodgson C: Creatine supplementation, sleep deprivation, cortisol, melatonin and behavior. Physiol Behav 2007, 90:21-8.

9. McMorris T, Harris RC, Swain J, Corbett J, Collard K, Dyson RJ, Dye L, Hodgson C, Draper N: Effect of creatine supplementation and sleep deprivation, with mild exercise, on cognitive and psychomotor performance, mood state, and plasma concentrations of catecholamines and cortisol. Psychopharmacology (Berl) 2006, 185:93-103.

10. Dworak M, McCarley RW, Kim T, Kalinchuk AV, Basheer R: Sleep and brain energy levels: ATP changes during sleep. J Neurosci 2010, 30:9007-16.

11. Gualano B, Artioli GG, Poortmans JR, Lancha Junior AH: Exploring the therapeutic role of creatine supplementation. Amino Acids 2010, 38:31-44.

12. Rae C, Digney AL, McEwan SR, Bates TC: Oral creatine monohydrate supplementation improves brain performance: a double-blind, placebocontrolled, cross-over trial. Proc Biol Sci 2003, 270:2147-50.

13. Atassi N, Ratai EM, Greenblatt DJ, Pulley D, Zhao Y, Bombardier J, Wallace S, Eckenrode J, Cudkowicz M, Dibernardo A: A phase I, pharmacokinetic, dosage escalation study of creatine monohydrate in subjects with amyotrophic lateral sclerosis. Amyotroph Lateral Scler 2010, Aug 11.Online Advance.

14. Lyoo IK, Kong SW, Sung SM, Hirashima F, Parow A, Hennen J, Cohen BM Renshaw PF: Multinuclear magnetic resonance spectroscopy of highenergy phosphate metabolites in human brain following oral supplementation of creatine-monohydrate. Psychiatry Res 2003, 123:87-100.

15. Lehmann KS, Martus P, Little-Elk S, Maass H, Holmer C, Zurbuchen U, Bretthauer G, Buhr HJ, Ritz JP: Impact of sleep deprivation on mediumterm psychomotor and cognitive performance of surgeons: prospective cross-over study with a virtual surgery simulator and psychometric tests. Surgery 2010, 147:246-54

16. Seng KY, Teo WL, Fun CY, Law YL, Lim CL: Interrelations between plasma caffeine concentrations and neurobehavioural effects in healthy volunteers: model analysis using NONMEM. Biopharm Drug Dispos 2010, 31:316-30

17. Harris RC, Nevill M, Harris DB, Fallowfield JL, Wise JA: Absorption of creatine supplied as a drink, in meat or in solid form. J Sports Science 2001, 20:147-151.

18. Persky A, Brazeau G: Clinical Pharmacology of the Dietary Supplement Creatine Monohydrate. Pharmacol Rev 2001, 53:161-176.

19. Hammett ST, Wall MB, Edwards TC, Smith AT: Dietary supplementation of creatine monohydrate reduces the human fMRI BOLD signal. NeurosCi Lett 2010, 479:201-5.

20. Blumert PA, Crum AJ, Ernsting M, Volek JS, Hollander DB, Haff EE, Haff GG: The acute effects of twenty-four hours of sleep loss on the performance of national-caliber male collegiate weightlifters. J Strength Cond Res 2007, 21:1146-54

21. Edwards BJ, Waterhouse J: Effects of one night of partial sleep deprivation upon diurnal rhythms of accuracy and consistency in throwing darts. Chronobiol Int 2009, 26:756-68.

22. Oliver SJ, Costa RJ, Laing SJ, Bilzon JL, Walsh NP: One night of sleep deprivation decreases treadmill endurance performance. Chronobiol Int 2009, 26:756-68
23. Kronholm E, Sallinen M, Suutama T, Sulkava R, Era P, Partonen T: Selfreported sleep duration and cognitive functioning in the general population. J Sleep Res 2009, 18:436-46.

24. Odle-Dusseau HN, Bradley JL, Pilcher JJ: Subjective perceptions of the effects of sustained performance under sleep-deprivation conditions. Chronobiol Int 2010, 27:318-33.

25. Maridakis V, Herring MP, O'Connor PJ: Sensitivity to change in cognitive performance and mood measures of energy and fatigue in response to differing doses of caffeine or breakfast. Int J Neurosci 2009, 119:975-94.

26. Sergi Ferre S: An update on the mechanisms of the psychostimulant effects of caffeine. J Neurochem 2008, 105:1067-1079.

27. Lara DR: Caffeine, mental health, and psychiatric disorders. J Alzheimers Dis 2010, 20:\$239-48.

28. Rawson ES, Lieberman HR, Walsh TM, Zuber SM, Harhart JM, Matthews TC: Creatine supplementation does not improve cognitive function in young adults. Physiol Behav 2008, 95:130-4

29. Verbessem P, Lemiere J, Eijnde BO, Swinnen S, Vanhees L, Van Leemputte M, Hespel P, Dom R: Creatine supplementation in Huntington's disease: a placebo-controlled pilot trial. Neurology 2003, 61:925-30.

30. Leproult R, Copinschi G, Buxton O, VanCauter E: Sleep loss results in an elevation of cortisol levels the next evening. Sleep 1997, 20:865-70.

31. Beaven CM, Hopkins WG, Hansen KT, Wood MR, Cronin JB, Lowe TE: Dose effect of caffeine on testosterone and cortisol responses to resistance exercise. Int J Sport Nutr Exerc Metab 2008, 18:131-41.

32. Stuart GR, Hopkins WG, Cook C, Cairns SP: Multiple effects of caffeine on simulated high-intensity team-sport performance. Med Sci Sports Exerc 2005, 37:1998-2005.

33. HoegerBement M, Weyer A, Keller M, Harkins AL, Hunter SK: Anxiety and stress can predict pain perception following a cognitive stress. Physiol Behav 2010, 101:87-92

34. Wingenfeld K, Schulz M, Damkroeger A, Philippsen C, Rose M, Driessen M: The diurnal course of salivary alpha-amylase in nurses: An investigation of potential confounders and associations with stress. Biol Psychol 2010, 85:179-181.

35. Cardinale $\mathrm{M}$, Stone $\mathrm{MH}$ : Is testosterone influencing explosive performance? J Strength Cond Res 2006, 20:103-7.

36. van der Merwe J, Brooks NE, Myburgh KH: Three weeks of creatine monohydrate supplementation affects dihydrotestosterone to testosterone ratio in college-aged rugby players. Clin J Sport Med 2009, $19 \cdot 399-404$

doi:10.1186/1550-2783-8-2

Cite this article as: Cook et al: Skill execution and sleep deprivation: effects of acute caffeine or creatine supplementation - a randomized placebo-controlled trial. Journal of the International Society of Sports Nutrition 2011 8:2.

\section{Submit your next manuscript to BioMed Central and take full advantage of:}

- Convenient online submission

- Thorough peer review

- No space constraints or color figure charges

- Immediate publication on acceptance

- Inclusion in PubMed, CAS, Scopus and Google Scholar

- Research which is freely available for redistribution

Submit your manuscript at www.biomedcentral.com/submit
C Biomed Central 